\title{
Human monocytes kill M-CSF-expressing glioma cells by BK channel activation
}

\author{
Neil T Hoa ${ }^{1}$, Jian Gang Zhang ${ }^{1,2}$, Christina L Delgado ${ }^{1}$, Michael P Myers ${ }^{3}$, Linda L Callahan ${ }^{4}$, Gerald Vandeusen ${ }^{3}$, \\ Patric M Schiltz ${ }^{5}$ H Terry Wepsic ${ }^{1,2}$ and Martin R Jadus ${ }^{1,2,6}$
}

In this study, human monocytes/macrophages were observed to kill human U251 glioma cells expressing membrane macrophage colony-stimulating factor (mM-CSF) via a swelling and vacuolization process called paraptosis. Human monocytes responded to the mM-CSF-transduced U251 glioma cells, but not to viral vector control U251 glioma cells (U251-VV), by producing a respiratory burst within $20 \mathrm{~min}$. Using patch clamp techniques, functional big potassium (BK) channels were observed on the membrane of the U251 glioma cell. It has been previously reported that oxygen indirectly regulates BK channel function. In this study, it was demonstrated that prolonged BK channel activation in response to the respiratory burst induced by monocytes initiates paraptosis in selected glioma cells. Forced BK channel opening within the glioma cells by BK channel activators (phloretin or pimaric acid) induced U251 glioma cell swelling and vacuolization occurred within $30 \mathrm{~min}$. U251 glioma cell cytotoxicity, induced by using BK channel activators, required between 8 and $12 \mathrm{~h}$. Swelling and vacuolization induced by phloretin and pimaric acid was prevented by iberiotoxin, a specific BK channel inhibitor. Confocal fluorescence microscopy demonstrated BK channels co-localized with the endoplasmic reticulum and mitochondria, the two targeted organelles affected in paraptosis. Iberiotoxin prevented monocytes from producing death in mM-CSF-expressing U251glioma cells in a $24 \mathrm{~h}$ assay. This study demonstrates a novel mechanism whereby monocytes can induce paraptosis via the disruption of internal potassium ion homeostasis.

Laboratory Investigation (2007) 87, 115-129. doi:10.1038/labinvest.3700506

KEYWORDS: paraptosis; macrophage colony-stimulating factor; monocytes; reactive oxygen species; potassium channels

Dying or dead cells can be described as possessing two distinct morphologies: apoptosis and necrosis. Paraptosis is thought to be the programmed form of cell death that culminates in necrosis. The mechanism by which paraptosis is induced is less well defined than the processes leading to apoptosis. Paraptotic cells are characterized by a swelling and vacuolization process that begins with physical enlargement of the endoplasmic reticulum (ER) and the mitochondria. ${ }^{1}$ The appearance of the swollen cells suggests ionic disregulation accompanied by water influx and retention. The disruption of intracellular ion homeostasis ultimately causes osmotic lysis releasing intracellular contents, such as ATP, $\mathrm{UTP}^{2}{ }^{2}$ high gel mobility binding protein-1 (HMGB1), ${ }^{3}$ heat-shock proteins ${ }^{4}$ and various proteases. These released substances act as 'danger signals' to promote massive inflammation, ultimately stimulating cell-mediated immunity. ${ }^{5,6}$ Apoptosis is distinguished by nuclear condensation, DNA cleavage, cell shrinkage, membrane blebbing and HMGB1 translocation to the nucleus. These events result in apoptotic body formation. ${ }^{3,7}$ Both professional phagocytes and adjacent stromal/parenchymal cells scavenge apoptotic bodies. ${ }^{8}$ Apoptosis has been called the 'silent death' because immunological responses are not provoked unless the cellular remnants are taken up by professional antigen-presenting cells (APC). ${ }^{9}$ In contrast, vaccination with necrotic tumor cells tends to produce superior T-cell immune responses. ${ }^{10,11}$ Steinman et $a l^{12}$ and Sauter et al ${ }^{13}$ demonstrated that exposure to necrotic cells allowed dendritic cells (DC) to mature more rapidly than exposure to apoptotic cells. Data presented by Fadok et al ${ }^{14}$ indicated that macrophages or DC fed apoptotic cells produced increased levels of immunosuppressive agents such as prostaglandin $\mathrm{E}_{2}$, platelet

\footnotetext{
Department of Diagnostic and Molecular Medicine, Veterans Affairs Medical Center, Long Beach, CA, USA; ${ }^{2}$ Department of Pathology, University of California, Irvine, CA, USA; ${ }^{3}$ Department of Chemistry and Biochemistry, California State University Long Beach, Long Beach, CA, USA; ${ }^{4}$ Department of Nursing, California State University Long Beach, Long Beach, CA, USA; ${ }^{5}$ Cell biology program, Hoag Cancer Center/Presbyterian Hospital, Newport Beach, CA, USA and ${ }^{6}$ Neuro-Oncology Program, Chao Comprehensive Cancer Center, University of California, Irvine, CA, USA

Correspondence: Dr MR Jadus, PhD, Diagnostic and Molecular Medicine Service, Veterans Affairs Medical Center, 5901 E 7th Street, Box 113, Long Beach, CA 90822, USA.E-mail: martin.jadus@med.va.gov
} 
activating factor, transforming growth factor- $\beta$ and interleukin-10. The presence of these soluble mediators prevented co-stimulatory molecules from being fully expressed by the APC. Reiter et $a^{15}$ also demonstrated better T-cell responses when necrotic cells were used as the stimulus.

Earlier, we reported that human U251 glioma cells (the U251-2F11 clone) transduced with membrane macrophage colony-stimulating factor (mM-CSF) were killed in vitro by mouse macrophages. HLA-A2 matched human peripheral blood mononuclear cells (PBMC) and enriched human monocytes/macrophages also killed these cloned glioma tumor cells in vitro. ${ }^{16}$ In vivo studies confirmed the lack of tumorigenicity of the U251-2F11 tumor cells in immunodeficient mice. In this same study it was demonstrated that rodent and human mononuclear phagocytes actively inhibited the growth of mM-CSF-transfected U251 glioma cells. After $4 \mathrm{~h}$, the mM-CSF transduced cells could be morphologically identified as paraptotic cells.

A putative molecular mechanism through which human monocytes produced death in mM-CSF-expressing U251 glioma cells via a disruption in ionic homeostasis was investigated in this current work. Evidence will be presented in which human monocytes were specifically observed to produce reactive oxygen species (ROS) after contacting mMCSF-expressing U251 glioma cells. This appears to be the initiating event that induces ionic disregulation within the glioma cells leading to paraptosis. Many glioma cells overexpress big potassium (BK) channels, which are thought to play a role in the invasive behavior of this cancer. ${ }^{17-19} \mathrm{BK}$ channels were not only detected on the membrane of the U251 glioma cells but also were proved to be functional by patch-clamping techniques. It has been reported that BK channels are indirectly regulated by oxygen. Two proteins, NADPH450 reductase and hemoxygenase-2, enzymatically control potassium channels by producing the secondary messenger, carbon monoxide (CO) in response to oxygen. ${ }^{20,21} \mathrm{CO}$, in turn, opens the $\mathrm{BK}$ channels allowing the exodus of intracellular $\mathrm{K}^{+}$ions. These $\mathrm{K}^{+}$-specific channels, also known as Maxi-K, hSlo, mSlo, calcium dependent $\left(\mathrm{BK}_{\mathrm{Ca}}\right)$, large conductance- or voltage-activated channels, ${ }^{17-19,22-27}$ regulate cell volume by controlling intracellular levels of potassium ions. Using BK channel activators, the BK channels were forced open within the glioma tumor target cells. This produced the same morphological changes observed in vivo when macrophages induced paraptosis in the mM-CSF-expressing U251 glioma cells. By flow cytometry, cell swelling was detected within 5 min after BK channel activation. The addition of phloretin or pimaric acid caused the tumor cells to form intracellular vacuoles visible by light microscopy within $30 \mathrm{~min}$. BK channels are found in the ER and the mitochondria ${ }^{26,27}$ suggesting a reason why these organelles are specifically affected in paraptosis. BK channel activation was required for $8-12 \mathrm{~h}$ to achieve cell toxicity. Iberiotoxin, a BK channel inhibitor, prevented vacuole formation in response to phloretin or pimaric acid. Iberiotoxin also prevented human monocytes from killing mM-CSF U251-2F11/TK cells in a $24 \mathrm{~h}$ assay. Data from the present study indicated that osmotic disregulation of the tumor cells induced by BK channel activation provided a possible mechanism through which monocyte-mediated cytotoxicity occurs. This was manifest in the observed specific cell swelling and vacuolization that are inherent in the process of paraptosis.

\section{MATERIALS AND METHODS \\ Cell Lines and Cell Culture}

The human U251 glioma cell line has been described previously. ${ }^{16}$ The U251 glioma cells, both those viral vector transduced with a non-inserted gene within the multicloning site of the LXSN retrovirus and the mM-CSF transduced U251-2F11 cells, were also transduced with a thymidine kinase (TK) suicide gene with a hygromycin selection marker (Dr Ralph Paul, Targeted Genetics, Seattle, WA, USA). The TK gene was transduced into the U251 cells as a safety measure for possible future therapeutic uses.

\section{Human Effector Cells}

After obtaining informed consent, PBMC from cancer patients undergoing various treatment therapies were collected by leukapheresis and ficolled. These samples were kindly provided by Dr Jeffrey Weber at the University of Southern California Norris Comprehensive Cancer Center (Los Angeles, CA, USA). The PBMC cells were resuspended at a concentration of $3-5 \times 10^{6}$ cells $/ \mathrm{ml}$ in DMEM media supplemented with $5 \%$ FBS. The cell suspension was added to FBS-pretreated dishes $(5 \mathrm{ml} /$ dish $)$ and incubated at $37^{\circ} \mathrm{C}$ for $1 \mathrm{~h}$, using standard monocyte enrichment techniques. The dishes were gently washed three times with PBS. The adherent cells were detached using $5 \mathrm{ml}$ of versene buffer (Invitrogen/Life Technologies, Carlsbad, CA, USA).

The leukocytes derived from cancer patients have been reported to be 'immunosuppressed or inhibited' owing to the effects of a variety of effector cells and molecules. These effector cells and molecules include $T$ regs, myeloid suppressor cells, immature DC, transforming growth factor- $\beta$, interleukin-10, prostaglandin, etc. ${ }^{28,29}$ These cells were specifically chosen for use because our long-term aim is to use mM-CSF transduced tumor cells as a possible vaccine. Any proposed tumor vaccine will involve interactions with these cells as opposed to cells derived from normal healthy donors. However, all of the responses discussed in this paper have been successfully reproduced using PBMC derived from normal individuals and with peritoneal-derived macrophages from rats.

\section{Chemicals}

Phloretin was purchased from Sigma Chemical Corp. (St Louis, MO, USA). Pimaric acid and recombinant iberiotoxin were obtained from Alomone Labs (Jerusalem, Israel). 


\section{ROS Detection}

Tumor cells or monocytes were prelabeled with $1 \mu \mathrm{M}$ $\mathrm{H}_{2}$ DCFDA (Molecular Probes, Eugene, OR, USA) for $15 \mathrm{~min}$ at $37^{\circ} \mathrm{C}$ according to the methods of Grzelak et al. ${ }^{30}$ The cells were washed three times and then added at a 10:1 monocyte:tumor concentration in either quadruple or sextuple replicates. The samples were analyzed using a Novostar Fluorometer (BMG Labtech, Offenburg, Germany).

\section{Electrophysiology}

Standard patch-clamp techniques were employed to record single-channel and macroscopic membrane currents. ${ }^{31,32}$ Patch pipettes were forged on a P-30 puller (Sutter Instruments, Novato, CA, USA) from thin-walled capillary glass (Warner Instruments, Holliston, MA, USA) resulting in resistances of 5-12 M $\Omega$. All protocols were run using PULSE software (HEKA Instruments, Port Washington, NY, USA) with a HEKA EPC10 amplifier (HEKA Instruments, Port Washington, NY, USA). Data were generated and stored directly in an ITC-1600 data acquisition system (HEKA Instruments, Port Washington, NY, USA). Data were filtered at $2 \mathrm{kHz}$ and acquired at $10 \mathrm{kHz}$. The seal resistance between the patch and the pipette was typically $>1 \mathrm{G} \Omega$. Cells were visualized with an Olympus IX51 inverted microscope (Olympus America, Melville, NY, USA). Grounding the recording chamber with an integral ground wire, sealed with agar and back filled with bath solution, minimized junction potentials produced by test solutions.

Solutions designed for recording of Maxi-K channels as described previously by Myers $e t a l^{33}$ were used. Briefly, the pipette solution consisted of: $140 \mathrm{mM} \mathrm{KCl,} 2 \mathrm{mM} \mathrm{MgCl}_{2}$, $1.1 \mathrm{mM}$ EGTA, $0.1 \mathrm{mM} \mathrm{CaCl}_{2}, 5 \mathrm{mM}$ HEPES and $5 \mathrm{mM} \mathrm{K}_{2}-$ ATP, at a $\mathrm{pH}$ of 7.3. The bath solution (extracellular solution) consisted of $140 \mathrm{mM} \mathrm{NaCl}, 2.8 \mathrm{mM} \mathrm{KCl}, 10 \mathrm{mM}$ HEPES, $0.10 \mathrm{mM} \mathrm{CaCl}_{2}$ and $10 \mathrm{mM}$ glucose, at a $\mathrm{pH}$ of 7.4. The concentration of free calcium in the pipette solution was calculated to be $16 \mathrm{nM}$, based on the use of a calcium buffer program (Guy.Droogmans@ med.KULeuven.ac.be).

Data were analyzed offline using ORIGIN software (version 6.1, Northampton, MA, USA). All curve fitting was performed using a least-squares curve fitting algorithm provided by the software. The conductance of the channels was calculated from the IV plots using unitary currents. The unitary currents were determined from Gaussian fits of amplitude frequency histograms.

\section{Immunofluorescence/Confocal Microscopy}

Adherent U251 glioma cells on sterile cover glass were cultured in DMEM media without serum. The cells were fixed with $2 \%$ paraformaldehyde, permeated in $0.2 \%$ Triton- $\mathrm{X}$ and probed with rabbit anti- $\mathrm{K}_{\mathrm{Cal} .1}\left(\mathrm{BK}_{\mathrm{Ca}}\right)$ antibody (Alomone Labs, Jerusalem, Israel). Mitochondria were stained with MitoTracker Deep Red (Molecular BioProbes/Invitrogen, Eugene, OR, USA). The ER was stained with goat antiGRP78 antibody (Santa Cruz Biotech, Santa Cruz, CA, USA).
The cover glass was incubated for $2 \mathrm{~h}$ with the primary antibody in a humidified chamber at $4^{\circ} \mathrm{C}$. The slides were washed three times in PBS. The slides were then incubated for $60 \mathrm{~min}$ after treatment with secondary fluorescein antirabbit antibody or Texas Red anti-goat antibody (Vector Labs, Burlingame, CA, USA). Finally, the cells were washed three times in PBS and mounted with ProLong Gold antifade reagent (Invitrogen, Carlsbad, CA, USA). Under certain circumstances, cells were counterstained with nuclei dyes. Sytox Green or Hoechst 33342 blue dye using Molecular BioProbes/ Invitrogen nuclear counterstaining kits were used according to the manufacturer's directions. Samples were imaged using a Nikon two laser (HeNe and Argon) PCM 2000 Confocal System on the Eclipse E800 Microscope. The two different fluorescent dyes in the labeled sample was simultaneously visualized through a single illumination and detection pinhole using the Compix Simple PCI software, so that there was exact pixel for pixel registration in both time and space for each dye in each channel. As a result, it can be inferred that the red emitting and green emitting probe are colorized when areas are present in the images shown in yellow. Fluorescence data quantitating the amount of area of fluorescence were analyzed using C-imaging software (Compix Incorporated, Tualatin, OR, USA). In the case of the size of the mitochondria, the cells were stained with MitoTracker Deep Red and then treated with nothing or with phloretin or pimaric acid. The area of total red fluorescence was then calculated according to number of pixels of screen covered in 10 individual cells from each treatment group and is presented as the average area \pm s.d. A Student's $t$-test was used to assess statistical differences.

\section{Real-Time Reverse Transcriptase Polymerase Chain Reaction}

Total RNA was isolated from the cells using Trizol reagent (Sigma Chemical Company, St Louis, MO, USA). Any possible DNA contamination in the sample was eliminated by an incubation with RNase-free DNase I digestion (Boehringer Mannheim GmbH, Germany). cDNA was synthesized using iScript $^{\mathrm{TM}}$ cDNA synthesis Kit (Bio-Rad Laboratories, Hercules, CA, USA) containing $1 \mu \mathrm{g}$ total RNA/sample. Real-time PCR reactions were performed on an iCycler iQ detection system (Bio-Rad Laboratories, Hercules, CA, USA) in conjunction with the SYBR Green kit (Stratagene, San Diego, CA, USA). The thermal profile was $95^{\circ} \mathrm{C}$ for $15 \mathrm{~min}$, followed by 40 cycles of $95^{\circ} \mathrm{C}$ for $15 \mathrm{~s}$ and $58^{\circ} \mathrm{C}$ for $30 \mathrm{~s}$, finally holding at $4^{\circ} \mathrm{C}$. The following primers were synthesized by Operon Biotech (Germantown, MD, USA): BK alpha channel forward: $5^{\prime}$-GATTGAGGAAGACACATGG- $3^{\prime}$ and reverse: $5^{\prime}$ CAGCTCACAAACAGTAGG- ${ }^{\prime}$. Samples were run in triplicate, and a reaction without CDNA was used to establish baseline fluorescence levels with 18S RNA. The fluorescent signal was plotted $v s$ cycle number, and the threshold cycle $\left(C_{\mathrm{T}}\right)$ was determined at the cycle number where an increase above background fluorescence could be reliably detected. 
Each PCR run also included non-template controls containing all reagents except cDNA. After cycling, a melting curve was produced by slow denaturation of the PCR end products to validate the specificity of amplification. The relative quantification of expression of the gene was determined by $2^{-\Delta \mathrm{CT}}$ as described by Pfaffl. ${ }^{34}$

\section{SiRNA of BK Channels within the U251-2F11/TK Cells}

We created two human BK channel specific primers using Invitrogen's Stealth ${ }^{\mathrm{TM}}$ SiRNA technology. Using primer set 1 ( $5^{\prime}$-UUUGAGUGAUGAUUCUUAUCUUCGG- $3^{\prime}$, and $5^{\prime}$-CC GAAGAUAAGAAUCAUCACUCAAA-3'; Cat\#1299003), 3 days after transfection with $40 \mathrm{pM}$ primer 1 (complexed with lipofectamine, Invitrogen) $95 \%$ of BK channel mRNA was suppressed as detected by real time-reverse transcriptase polymerase chain reaction. Using $80 \mathrm{pM}$ of primer set 1 , BK channel mRNA was undetectable on day 3 after transfection. With primer set 2 (5'-UUAAGCAGAAGAUCAGGUCCGUC GG-3' ${ }^{\prime}$ and $5^{\prime}$-CCGACGGACCUGAUCUUCUGCUUAA- ${ }^{\prime}$ ): $40 \mathrm{pM}$ produced $21 \%$ BK channel mRNA of control values, whereas $80 \mathrm{pM}$ produced $95 \%$ inhibition. These values were maintained when this experiment was analyzed 4 days after the initial transfection. As primer set 1 was the most effective, we chose this to use in further experiments.

Three to four days after the U251-2F11/TK cells were transfected with Primer Set 1, these cells were measured by immunofluorescence microscopy with the anti-BK antibody (rabbit anti- $\mathrm{K}_{\mathrm{Cal.1}}\left(\mathrm{BK}_{\mathrm{Ca}}\right)$ ) to verify that $\mathrm{BK}$ channel protein expression was indeed knocked down. The amount of the fluorescence was captured using the confocal microscopy and quantitated by the Compix software. When phloretin was added to these siRNA-transfected cells, no swelling or vacuolization was seen after $12 \mathrm{~h}$. By $24 \mathrm{~h}$, there were no signs of cell death within the siRNA-treated U251-2F11/TK, while the control (non-siRNA treated) cells were dead. Cytotoxicity was measured using Invitrogen's Vybrant CFDA SE Kit.

\section{RESULTS \\ Monocytes in Response to mM-CSF Tumor Cells Make ROS}

Macrophages derived from rodent bone marrow have been observed to kill mM-CSF tumor cells through a phagocytosis mediated pathway. ${ }^{35,36}$ The mechanism by which freshly isolated human monocytes/macrophages killed the mM-CSFtransduced cells was unknown. The $\mathrm{H}_{2}$ DCFDA luminescent method was used to determine if ROS are made in cultures of human monocytes responding to U251-2F11/TK cells.

The time kinetics of monocyte (prelabeled with $\mathrm{H}_{2}$ DCFDA) response to the U251 and U251-2F11 cells was monitored using a luminometer to measure the production of ROS (Figure 1a). The singly cultured U251-2F11/TK glioma cells and monocytes demonstrated flat baseline values. When the human monocytes were co-cultured with the U251-VV/TK cells, an initial rise in the ROS production was similar to that observed in the untreated monocytes. By
30 min there was a significant $(P<0.05)$ elevation of the ROS generated by the monocytes in response to the mM-CSF-expressing U251 cells. This strong level of ROS induction continued for the next $120 \mathrm{~min}$, the duration of the experiment. From these data, it was concluded that ROS species are produced relatively quickly in response to mM-CSF-expressing tumor cells and significant levels are maintained for at least $2 \mathrm{~h}$.

Figure 1e-g, shows that within $20 \mathrm{~min}$, a different set of monocytes exposed to the U251-2F11/TK cells (prelabeled with $\mathrm{H}_{2}$ DCFDA) (panels $\mathrm{f}$ and g) produced more chemiluminescence than the monocytes responding to the prelabeled viral vector control U251 cells at the same time points (panels $c$ and d). Thus, ROS are only present within the targeted U251-2F11TK cells.

\section{U251 Cells Possess Functional BK Channels}

Many glioma cells express or overexpress BK channels. ${ }^{17-19,22-27}$ The following mechanism has been proposed to explain how $\mathrm{BK}$ channels can be regulated by oxygen. ${ }^{20,21}$ In the presence of $\mathrm{O}_{2}$, or other oxygen species, an electron is transferred from heme by NADPH 450 reductase to hemoxygenase-2, thereby enzymatically generating $\mathrm{CO}$. The presence of $\mathrm{CO}$ opens the BK channels allowing the efflux of $\mathrm{K}^{+}$ions from intracellular pools. As the monocytes produce a respiratory burst containing various oxygen species in response to membrane M-CSF found on U251 glioma cells, it is hypothesized that this upstream reaction initiates the process of cellular death.

With the use of an anti-BK channel antibody, the presence of cell-surface BK channels was detected by immunofluorescence techniques. Standard patch clamping techniques further demonstrated that the U251 glioma cells had functional cell surface BK channels. Cell attached recordings of the U251 glioma cells (Figure 2) revealed large conductance channels consistent with BK channels previously characterized within glioma cells in other studies. ${ }^{22-27}$ Panel a illustrates the conductance results of cells receiving depolarizing pulses, whereas panel $\mathrm{c}$ shows the cellular responses to hyperpolarizing pulses. The presence of BK channels was demonstrated using both negative (panel $b$ ) and positive (panel d) test potentials when the pipette potential was ramped +100 to $-100 \mathrm{mV}$ from a holding potential of $0 \mathrm{mV}$. The resulting conductance currents showed strong voltage dependence and single-channel currents were resolved in these patches. The unitary slope conductance of the single-channel currents was greater than $150 \mathrm{pS}$. The transmembrane potential in the cell-attached patch configuration was measured because the membrane was intact and the actual membrane potential was unknown. The membrane potential was estimated by breaking the patch at the end of the experiment or the average value from whole cell recordings was used. The gathered data closely matched that of Maxi-K channels observed in STTG-1 glioma cells using the same techniques and voltages. ${ }^{18}$ These results indicated that U251 glioma cells express functional BK channels at the cell surface. 

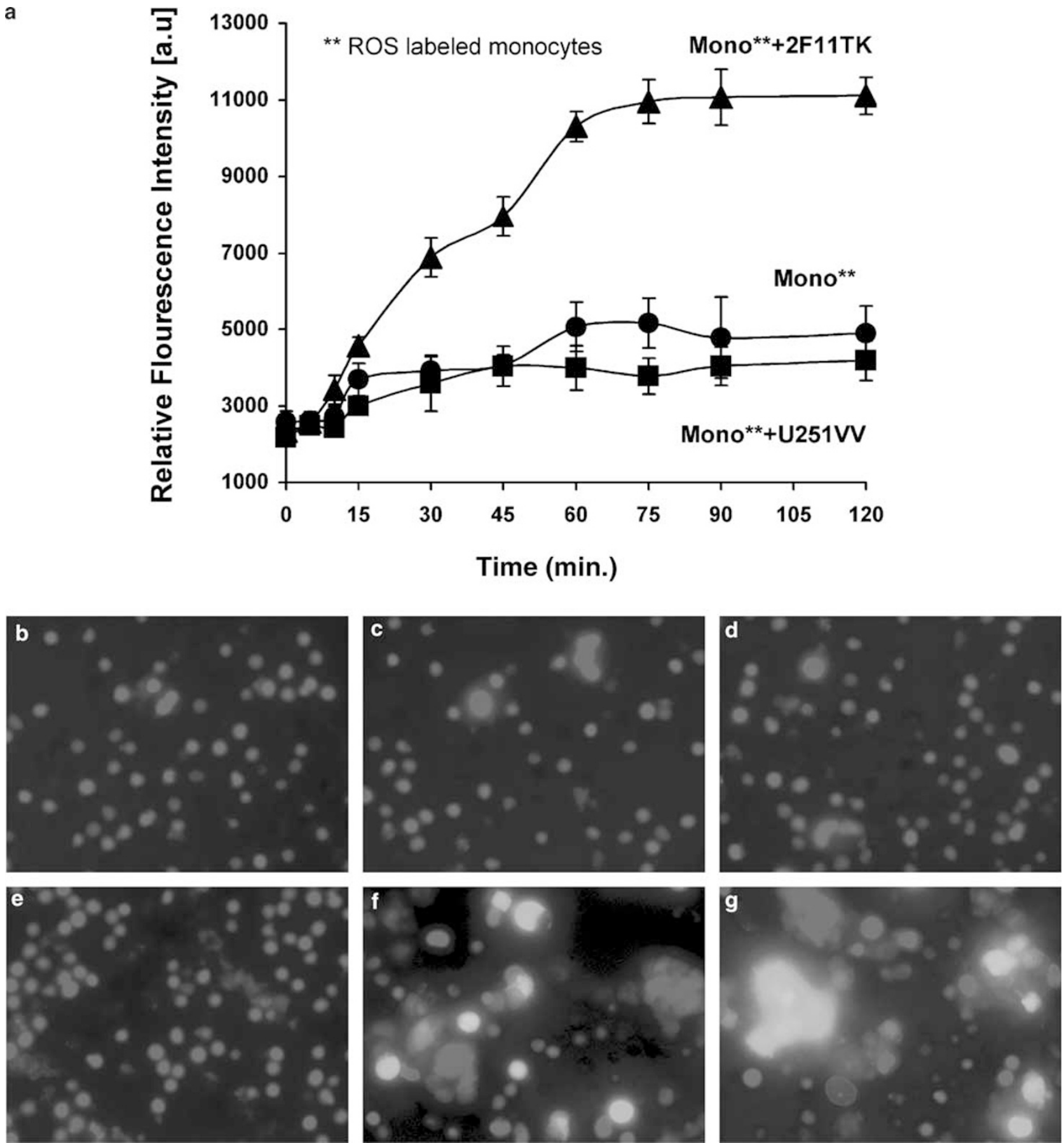

Figure 1 ROS production is induced within cultures of monocytes responding to mM-CSF-expressing U251 cells. The top panel (a) shows the time kinetics of the chemiluminescence produced by $\mathrm{H}_{2}$ DCFDA prelabeled monocytes in response to the U251-VV or U251-2F11/TK cells or by the monocytes alones. Each point represents the response obtained from sextuple cultures \pm s.d. Beginning at $30 \mathrm{~min}$ and throughout the remaining experimental time, the fluorescence readings of the monocytes responding to the U251-2F11/TK were significantly different $(P<0.05)$ from the monocytes responding to the U251VV cells or the monocytes incubated without any tumor cells. U251-VV/TK and U251-2F11/TK were prelabeled with $\mathrm{H}_{2}$ DCFDA dye and incubated with human monocytes. The monocytes and glioma cells were counterstained with a blue nuclear dye. The middle panels (b-d) illustrate the time course progression of U251-VV cells and monocytes at times 0,20 and $40 \mathrm{~min}$, respectively. The bottom panels (e-g) indicate the chronology of events when the monocytes reacted with U251-2F11/TK cells at the same time intervals listed in panels b-d.

\section{BK Channel Activators Induce U251 Glioma Cells to Swell and Form Vacuoles}

It was hypothesized that a forced opening of the BK channels within the glioma cells as a result of ROS from the monocytes would disrupt the normal internal ion homeostasis of the targeted cell. Once activated BK channels allow an osmotic imbalance to develop that initiates the swelling process seen in paraptosis. The BK channel activators, phloretin or 

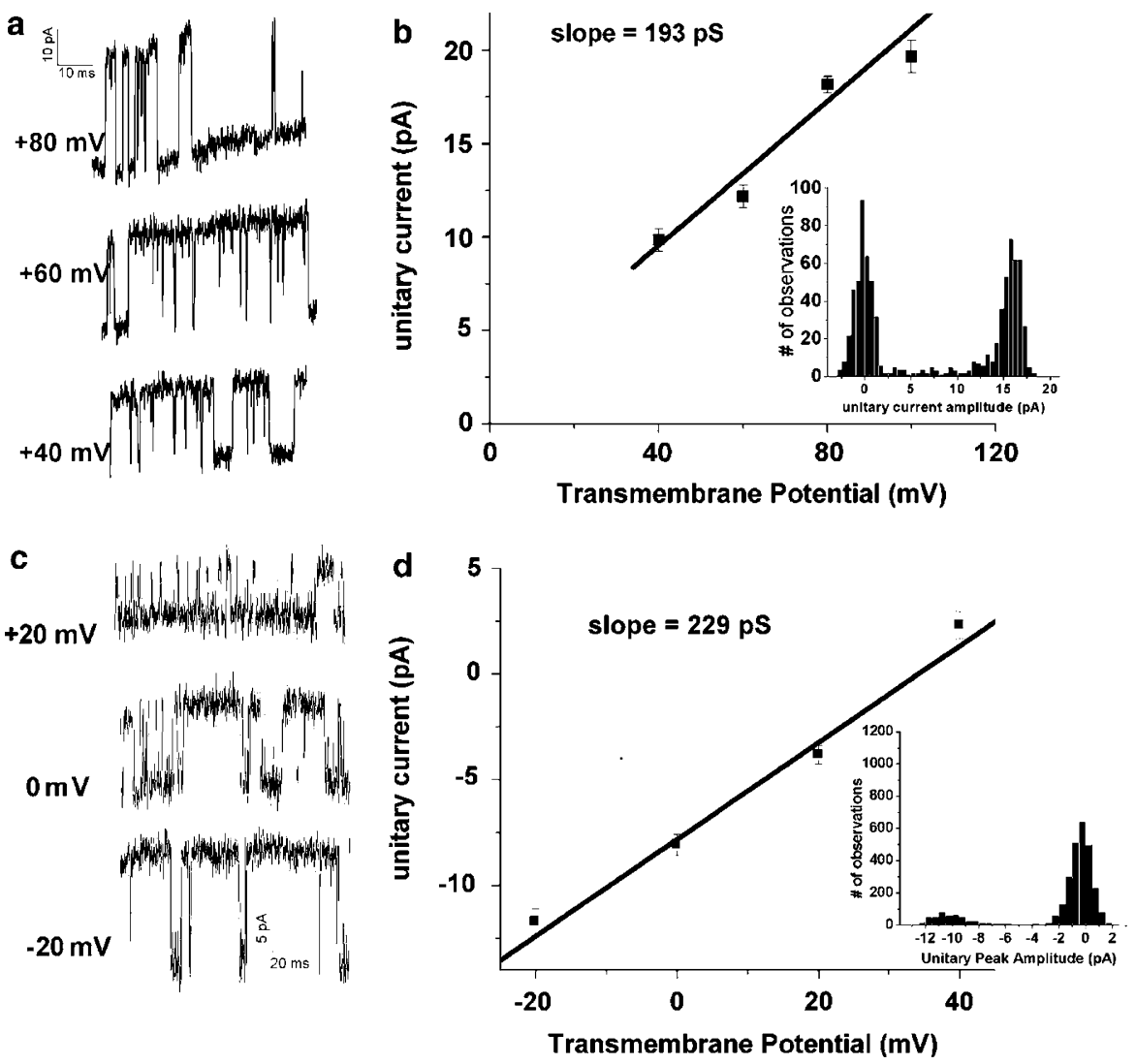

Figure 2 U251glioma cells possess functional BK channels as demonstrated by patch-clamping techniques. Cell attached recordings of Maxi-K channels in U251 cells. (a) Representative traces from a cell-attached patch in response to depolarizing pulses. (b) Unitary current-voltage relationship of the channels at positive potentials. The inset is an amplitude histogram (bin width is $0.5 \mathrm{pA}$ ) obtained at a transmembrane potential of $+80 \mathrm{mV}$ (see Materials and methods for details). The slope of this line indicates a conductance of $193 \mathrm{pS}$. (c) Representative traces from a cell-attached patch in response to hyperpolarizing pulses. (d) Unitary current-voltage relationship of the channels at mainly negative potentials. The inset is an amplitude histogram (bin width is $0.5 \mathrm{pA}$ ) obtained at a transmembrane potential of $-20 \mathrm{mV}$. The slope of this line indicates a conductance of $229 \mathrm{pS}$. Both IV plots were constructed from three separate cells each $(n=3)$ and error bars represent the values \pm the s.e.m. pimaric acid, and hydrogen peroxide $\left(\mathrm{H}_{2} \mathrm{O}_{2}\right)$ (not shown), a monocyte/macrophage-derived product, were used to determine if cell swelling could be induced. Figure 3a illustrates that the U251 glioma cells became enlarged within $15 \mathrm{~min}$ in the presence of the BK channel activators. The observed swelling was maintained at $30 \mathrm{~min}$ and continued to be present until the experiment was stopped at $60 \mathrm{~min}$. The swelling effect produced by phloretin and pimaric acid was prevented by using the BK channel inhibitor, iberiotoxin. Initially, before the cell swelling, within 5-10 min, the cells actually shrank. The prolonged swelling of the U251 glioma cells in response to phloretin and pimaric acid treatment suggests that activation of the BK channels produces immediate physical effects on the target cell. Iberiotoxin also prevented cell swelling in response to $\mathrm{H}_{2} \mathrm{O}_{2}$ (Figure 3b), suggesting that the $\mathrm{H}_{2} \mathrm{O}_{2}$ can control the functions of $\mathrm{BK}$ channels.

Flow cytometry initially screens cells for forward scatter, which is indicative of size. The cells are simultaneously analyzed for $90^{\circ}$ side scatter, thereby measuring internal structure or granularity. During the performance of flow cytometric analysis, the observed cells simultaneously gained in the side scatter, mean peak channel number. This increased granularity was interpreted to mean that vacuolization was simultaneously occurring. Another set of BK channel-activated U251 glioma cells were examined using light micro- scopy to confirm the interpretation of the previous flow cytometric results. Adherent U251 glioma cells were exposed to BK channel activators. Non-treated U251 glioma control cells remained healthy (Figure 3c). In contrast, after $30 \mathrm{~min}$ phloretin treated cells became vacuolated (panel d). After $1 \mathrm{~h}$, these cells were extremely distended (panel e). Under the same conditions, identical results were observed with the use of pimaric acid (panel g). Iberiotoxin, a specific BK channel inhibitor, when used with pimaric acid successfully blocked the swelling and vacuolization effects of the pimaric acid on the U251 glioma cells (Panel h). Iberiotoxin also prevented the vacuolization of phloretin-treated cells (data not shown).

\section{Cell Cytotoxicity Occurred after 8-12 h of Continuous BK Channel Activation}

The exact point at which cytotoxicity occurred was determined by performing $\mathrm{Cr}^{51}$ release studies (Figure 4). Minimal cytotoxicity occurred after $4 \mathrm{~h}$ when any of the BK channel activators were applied. No cytotoxicity was seen despite $4 \mathrm{~h}$ of exposure to these drugs even though the cells were greatly stressed after only $30 \mathrm{~min}$ to $1 \mathrm{~h}$ of treatment as seen in Figure $3 \mathrm{~d}$ and e. These data indicated that the cells' membranes were still intact and able to retain the radioisotope. At $8 \mathrm{~h}$, early signs of cytotoxicity were observed, although the cellular death 

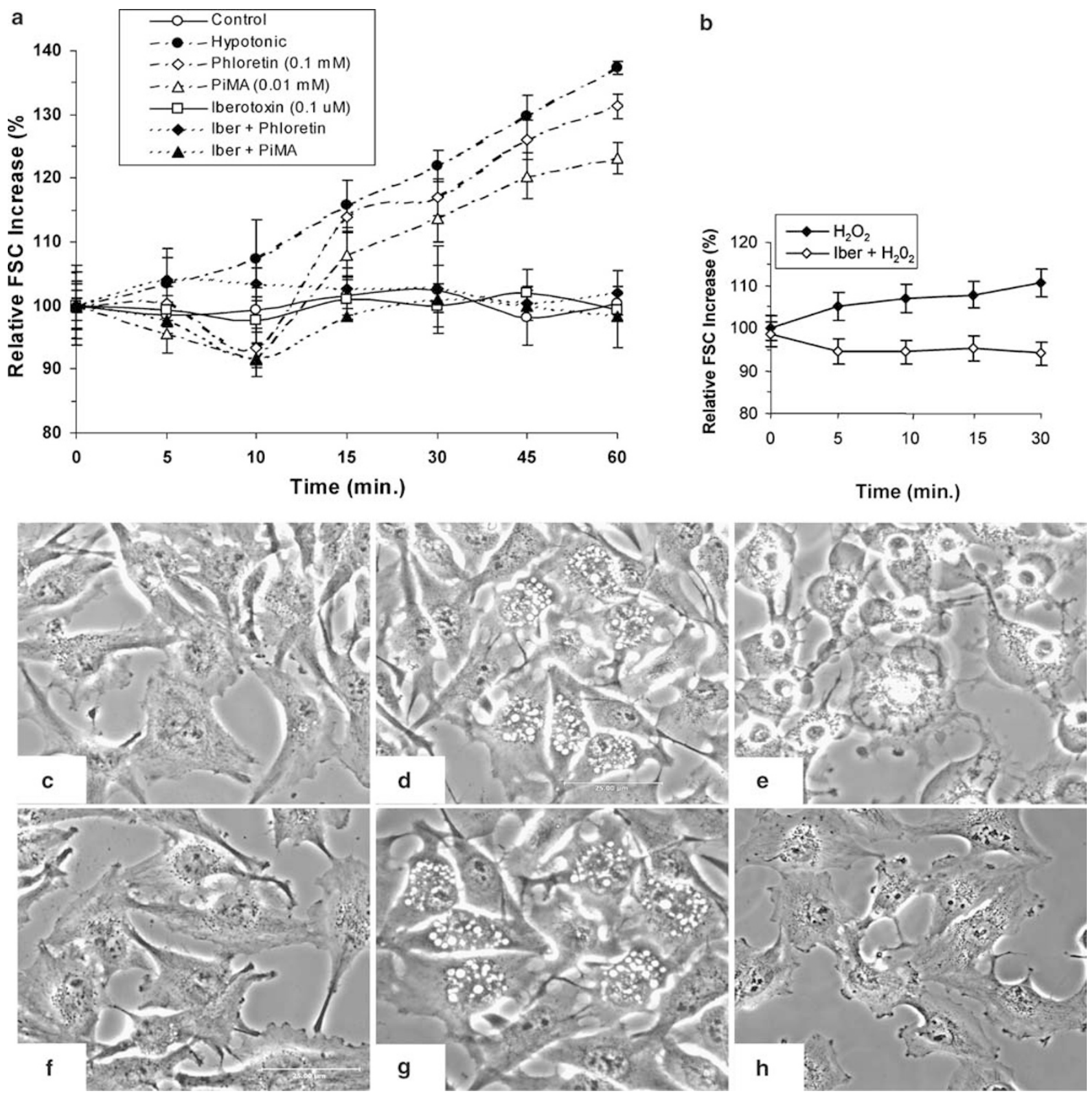

Figure 3 BK channel activators produced increased cell size and vacuolization within $1 \mathrm{~h}$. U251 glioma cells were exposed to $0.01 \mathrm{mM}$ pimaric acid, $0.1 \mathrm{mM}$ phloretin or $0.1 \mu \mathrm{M}$ iberiotoxin at $37^{\circ} \mathrm{C}$. (a) Ten thousand cells were analyzed on the flow cytometer for cell size (forward scatter) after $5,10,15,30,45$ and $60 \mathrm{~min}$. The mean peak channel number of the untreated cells at each time point was taken as $100 \%$. (b) Iberiotoxin $(0.05 \mu \mathrm{M})$ prevents $\mathrm{H}_{2} \mathrm{O}_{2}(1 \mathrm{mM})$ from inducing cell swelling. (c) Adherent untreated, control U251 cells, or U251 cells incubated for $30 \mathrm{~min}$ (d), and after $1 \mathrm{~h}$ in $0.2 \mathrm{mM}$ phloretin (e). The cells are greatly distended. The bottom row of panels represent the cultures of the U251 glioma cells pretreated for $1 \mathrm{~h}$ with $0.05 \mu \mathrm{M}$ r-iberiotoxin (f) and U251 glioma cells after pimaric acid treatment $(0.01 \mathrm{mM})$ for $30 \mathrm{~min}(\mathbf{g})$. The right panel (h) shows the blocking effect of iberiotoxin pretreatment upon the expected cellular effect of pimaric acid $(0.01 \mathrm{mM})$ exposure for $30 \mathrm{~min}$.

was not statistically significant. At $12 \mathrm{~h}$, cytotoxicity was maximal in cells with exposure to the two highest concentrations of phloretin $(0.5$ and $0.1 \mathrm{mM})$ and pimaric acid $(0.05$ and $0.01 \mathrm{mM})$. Thus, actual cell death required an extended time in addition to the initiation time for swelling and vacuolization.

\section{BK Channels are Found in the Targeted Organelles of Paraptosis}

Immunofluorescent confocal microscopy techniques utilizing a BK-specific antibody allowed identification of the locations of the BK channels within the U251 glioma cells. The top (Figure 5a) and bottom left panels (Figure 5d) demonstrate 
that the BK channels were found at several locations within the cell. BK channels were observed at intracellular sites as well as along the edges of the cell membrane.

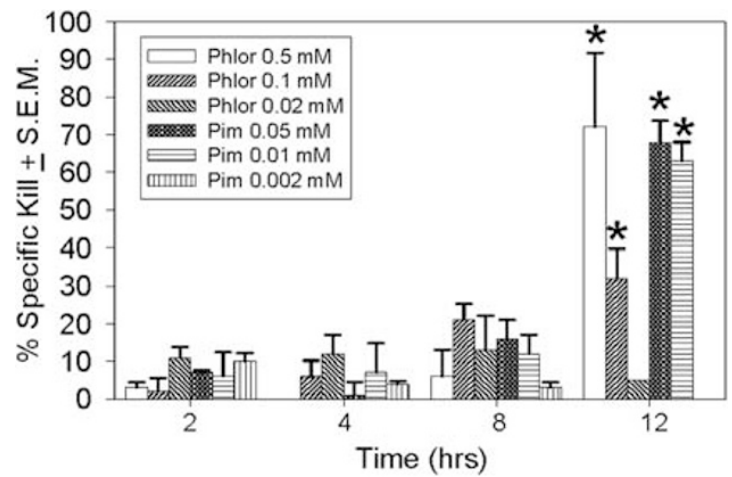

Figure 4 Phloretin and pimaric acid produce the death of the glioma cells following 8-12 h of exposure. One million $\mathrm{Cr}^{51}$-labeled $\mathrm{U} 251$ glioma cells were incubated with $0.5,0.1$ or $0.02 \mathrm{mM}$ phloretin or $0.05,0.01$ or $0.002 \mathrm{mM}$ pimaric acid in 24-well plates. Samples of the cultures were harvested after $2,4,8$ and $12 \mathrm{~h}$. Data show the percent of specific release, \pm s.e.m. of triplicate cultures. The spontaneous release in this experiment was $25 \%$ of the total release. The asterisk represents a significant difference $(P<0.05)$.
Co-localization studies to identify the intracellular location of the BK channels were performed. In these studies the mitochondria were stained with a specific red stain (Mito-tracker red) (panel b) in combination with the green fluorescent anti-BK channel antibody. In the merged figure (panel c), yellow staining was seen in many sites within the cells where the mitochondria are found. Additional sites of green fluorescence were interpreted to mark non-mitochondrial organelles such as the ER or the Golgi apparatus. A similar approach was used to stain the ER with red fluorescent mouse anti-GRP78 antibody (panel e) and the anti-BK channel antibody. The BK channels and the ER appeared to co-localize together (panel f).

It was possible to demonstrate fluorescent mitochondrial swelling in response to BK channel activators. The mitochondria were first stained with Mito-tracker-red and then the cells were treated with the BK channel activators for $1 \mathrm{~h}$. Figure 6, left panel shows the presence of small red mitochondria in a fine fibrous distribution throughout the untreated cells. Those cells treated with either phloretin (middle panel) or pimaric acid (right panel) were observed to possess many enlarged red fluorescent mitochondria. Red vacuoles were seen within the pimaric acid-treated cells. The
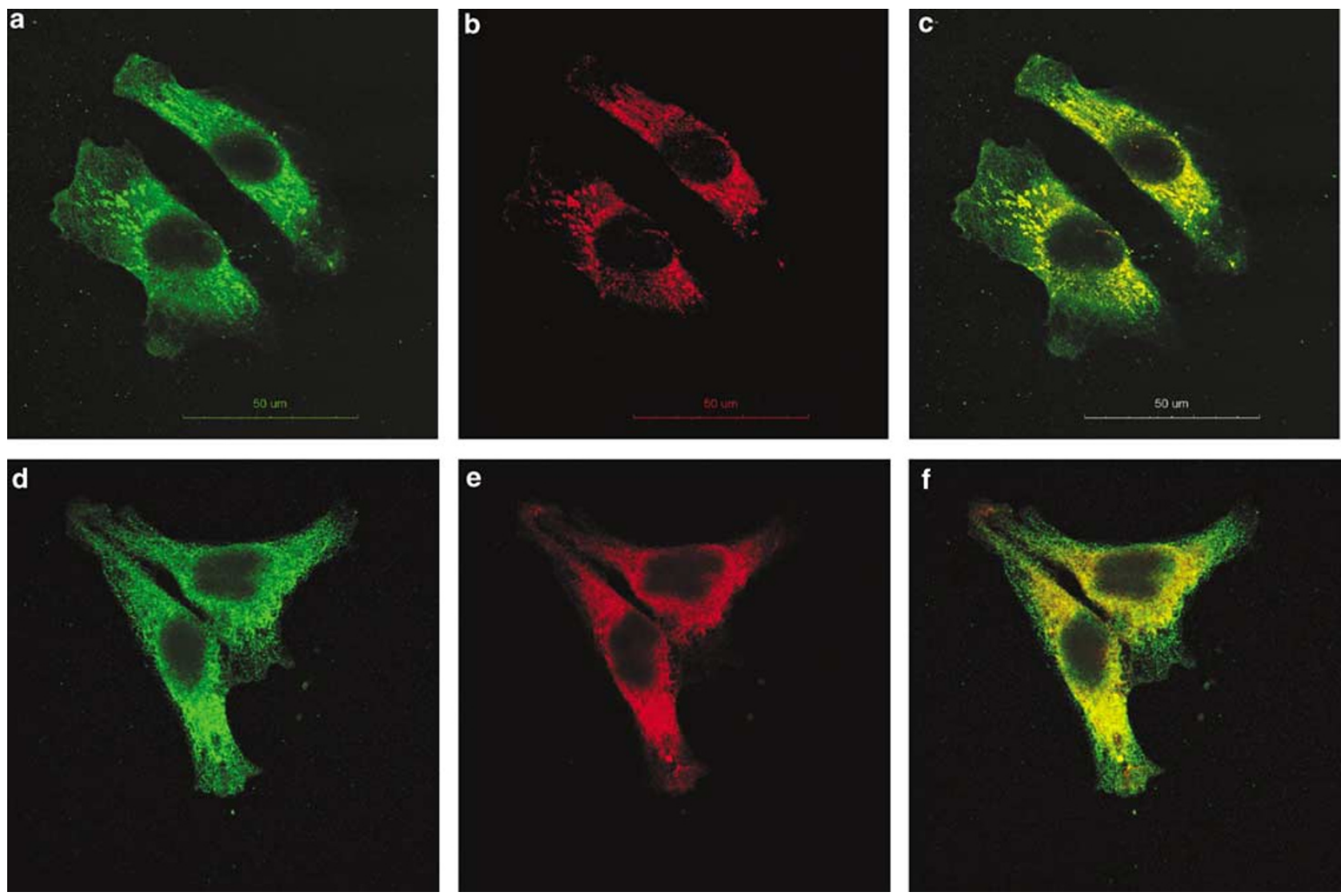

Figure 5 U251 glioma cells display BK channels in multiple cellular sites. Top row of panels: cells viewed with exposure to only the anti-BK channel antibody (a); middle panel: the cells viewed have been treated with Mito-tracker Red (b); merger of cells in left and middle panels (c). The right row of panels show another preparation of the U251 glioma cells stained with BK channel antibody (d). The middle panel (e) displays the cells stained with anti-GRP78 antibody and PE-conjugated secondary antibody, indicative of the ER. The merged figures (f) in one plane show yellow color where co-localization has occurred. 
red mitochondria from 10 cells within each treatment group were then analyzed by the Compix software, which quantitates the area of red fluorescence of the mitochondria. The bar chart shows that the mitochondria from the phloretin and pimaric acid-treated U251 cells are indeed significantly $(P<0.001)$ swollen.

\section{Human Monocytes Induce Swollen Target Cell Mitochondria after a 4-h Interaction with mM-CSF-Expressing U251-2F11/TK Glioma Cells}

The use of Mito-tracker red dye to specifically stain the target cell's mitochondria allowed demonstration of the presence of immediate effects within the U251-2F11/TK cells upon contact with the monocytes. The target cells' mitochondria were stained red while the nuclei were counterstained green (Figure 7). Co-culture studies were carried out for $4 \mathrm{~h}$. The top panel (a) illustrates that after $4 \mathrm{~h}$ of incubation without monocyte addition, normal red mitochondria were unaffected within the control, non-treated U251-2F11/TK cells. Monocytes that physically contacted the mM-CSF-expressing tumor cells induced mitochondria swelling (panel c). The monocytes displayed a well-defined green nuclear stain without any mitochondrial staining. When the monocytes were incubated with the U251 cells, monocyte/glioma cell clusters formed (panel b: U251; panel c: U251-2F11/TK). Little mitochondrial swelling occurred when the monocyte
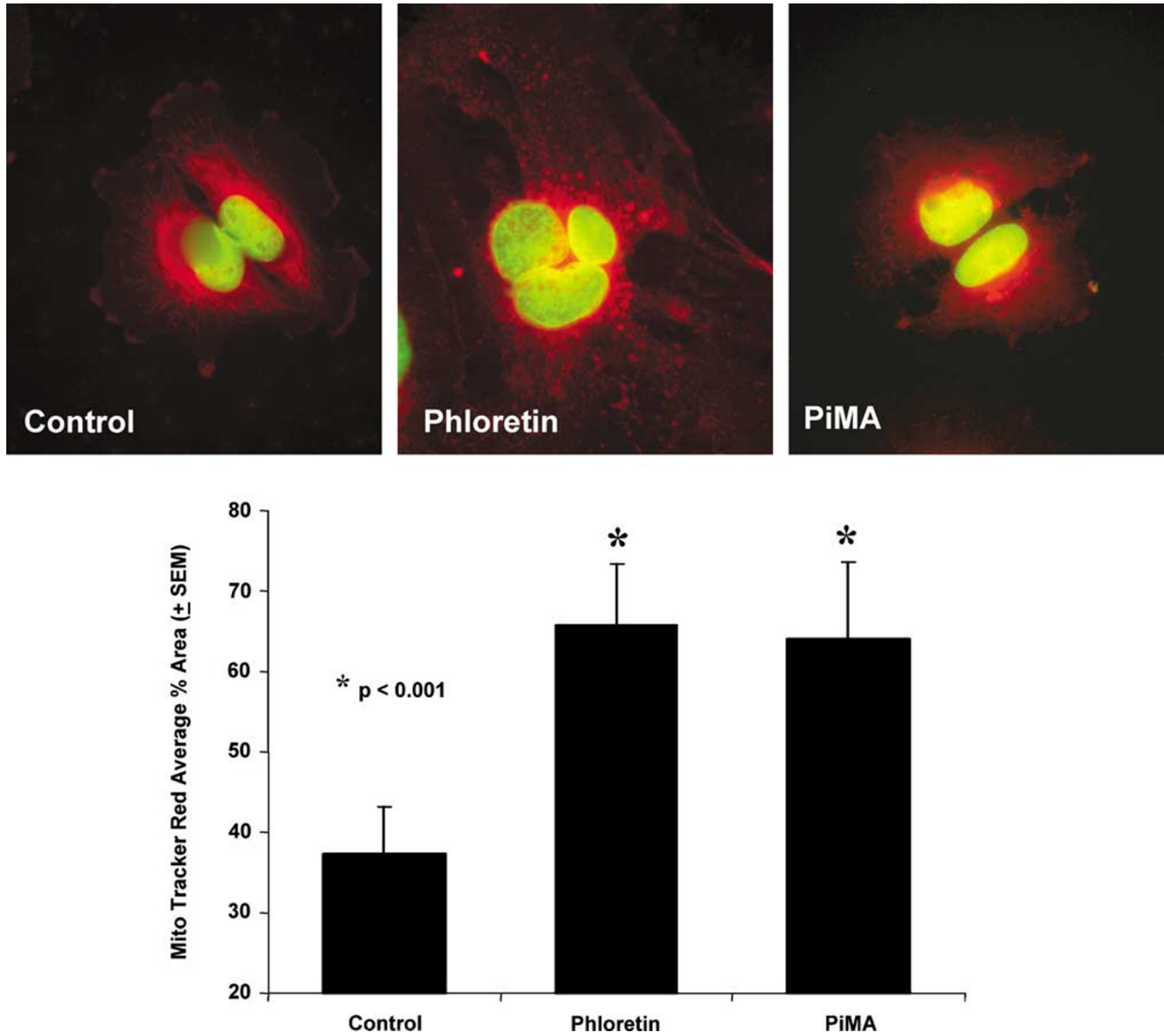

Figure 6 Treating U251 glioma cells with phloretin and pimaric acid induced swelling of the mitochondria. Cells were loaded with Mito-tracker-red and then exposed to either $0.1 \mathrm{mM}$ phloretin (middle panel) or $0.01 \mathrm{mM}$ pimaric acid (right panel) for $1 \mathrm{~h}$. The mitochondria within the untreated control cells (left panel) show small-defined mitochondria, whereas the mitochondria of the BK channel-activated cells are swollen (middle and right panels) and vacuolization is present (right panel). The nuclei are counterstained green. The bar chart summarizes the area of red fluorescence from 10 different cells from each experimental conditions. The asterisk indicates a $P<0.001$ as determined by a Student's $t$-test. 
interacted with the U251-VV cells. When monocytes interacted with U251-2F11/TK glioma cells (panel c), these affected glioma cells displayed swollen mitochondria as a result of the physical attachment of two monocytes to the cell membrane. An unaffected glioma cell is immediately adjacent to the effected glioma cell (left of the glioma with the swollen cells). This figure supports the observation that monocytes must come in direct contact with the targeted cells before mitochondrial damage can occur.

\section{In a $24 \mathrm{~h}$ Assay, Iberiotoxin, a Specific BK Channel Inhibitor, Prevented Monocyte-Mediated Death of mM-CSF U251-2F11/TK Cells}

It was possible to prove that the monocyte-mediated death of mM-CSF-expressing U251-2F11/TK glioma cells could be prevented by instituting BK channel inhibition of the target cells. Figure 8 demonstrates that the use of $100 \mathrm{nM}$ iberiotoxin inhibited monocyte-induced death of U251-2F11/TK cells at a 10:1 monocyte:tumor ratio. The monocytes produced a $69 \pm 1.3 \%$ specific release, while the presence of the iberiotoxin reduced the incidence of cellular death to $16 \pm 2.3 \%$. The presence of iberiotoxin significantly $(P<0.001)$ reduced lysis of the U251-2F11/TK cells by $77 \%$, indicating that monocyte-dependent death of the mM-CSFexpressing glioma cells was produced through a BK channeldependent pathway.

siRNA Treatment of BK Channels in U251-2F11/TK Cells
Knocks Down BK Channels and Makes the U251-2F11/TK
Cells Resistant to the Effects of the Cytotoxic Monocytes Cells Resistant to the Effects of the Cytotoxic Monocytes
We employed siRNA technology to genetically knock down the expression of BK channels within the U251-2F11/TK cells. Three siRNA primers were initially designed. Two of the three primers proved effective in knocking down the expression of the $\mathrm{BK}$ channels using real-time reverse transcriptase PCR (RT-RT/PCR) 2-4 days after siRNA transfection into the U251-2F11/TK cells. Primer set 1 proved to be most effective in keeping the expression of BK channels down by $25-99 \%$. This primer was then used for further work. Figure 9a show the green fluorescence staining profiles of representative U251-2F11/TK cells stained for BK channels. The right panel shows the staining profile of the untreated U251-2F11/TK cell showing high intensity of BK channels. The middle panel shows the staining of the siRNA-treated U251-2F11/TK cells, which is similar to the negative control staining (no primary antibody). The bar chart in Figure $9 \mathrm{~b}$ shows the fluorescence intensity of 10 representative cells

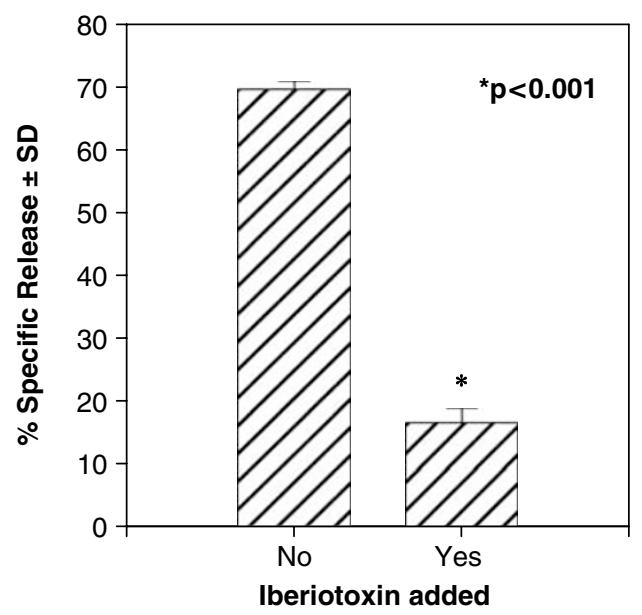

Figure 8 Iberiotoxin prevents human monocytes from killing U251-2F11/ TK cells. The U251-2F11/TK cells were incubated with human monocytes at a 10:1 concentration in quadruple cultures. Iberiotoxin $(0.1 \mu \mathrm{M})$ was added at the start of the reaction. The culture was then analyzed at $24 \mathrm{~h}$. The asterisk indicates a $P$-value $<0.001$.
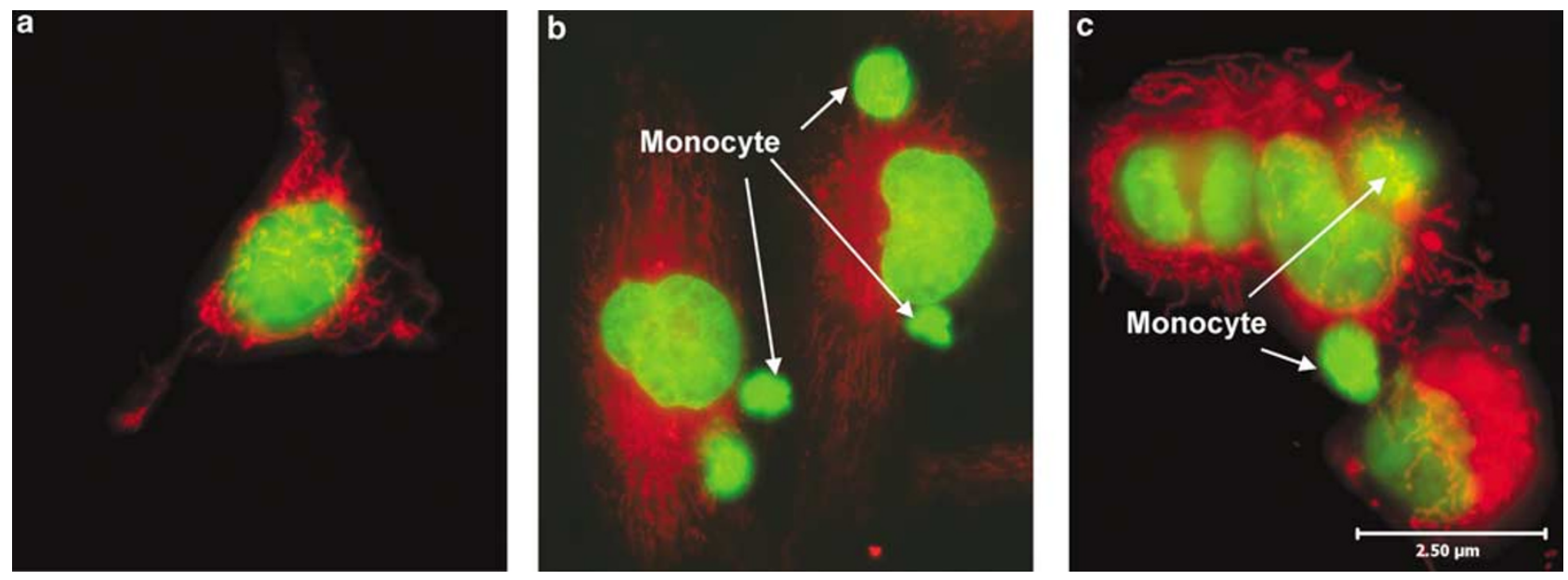

Figure 7 Monocytes induce mitochondrial swelling of the targeted cells after $4 \mathrm{~h}$ of co-culture. U251-2F11/TK cells were stained with Mito-tracker red, whereas the monocytes were stained only with green nuclear stain. The cells were co-incubated together for $4 \mathrm{~h}$ at $37^{\circ} \mathrm{C}$. The left panel (a) shows the unaffected, cultured clone U251-2F11/TK cells with small normal mitochondria. The middle panel (b) demonstrates the monocytes responding to the U251VV cells. The right panel (c) shows the monocytes causing the mitochondria of the U251-2F11/TK to swell. The arrows point to green nuclear stained human monocytes in direct contact with the U251cells. 
from each condition. When human monocytes at a 10:1 monocyte:tumor ratio were co-cultured with another set of these various U251 cells that were prelabeled with the Vybrant CFDA fluorescent dye, there was definite signs that the monocytes failed to kill the siRNA-knocked down U251-2F11/TK cells, whereas non-treated U251-2F11/TK cells showed signs of cytotoxicity by $18-24 \mathrm{~h}$.

\section{DISCUSSION}

A number of different tumor cells (human U251 glioma, rat T9/9L glioma, rat MADB106 breast cancer and mouse Hepa1-6 hepatocellular carcinoma) that express mM-CSF have failed to form either subcutaneous or intracranial tumors in rodents. ${ }^{16,35-40}$ Tumor cells transduced with the secreted form of M-CSF were not killed by monocytes/ macrophages in vitro and were capable of forming tumors in immunocompetent animals. This finding is consistent with various human tumors that normally produce M-CSF, such as breast, ${ }^{41}$ ovarian ${ }^{42}$ and some glioma ${ }^{43}$ tumors. Here, the sM-CSF stimulated macrophages help the tumor grow $^{38}$ by releasing various growth factors and aid metastasis by producing proteolytic enzymes. We have hypothesized that the presence of $\mathrm{mM}$-CSF allows prolonged physical conjugation between transduced tumor cells and myeloid cells, facilitating cytotoxicity and producing antitumor immunity. ${ }^{44}$ In all of the animal tumor models, it was observed that the animals were immunized to the unmodified parental tumor cells after being exposed to living mM-CSF-transduced cells. At that time it was thought that the animals achieved their immunity due to the macrophages acting as the APC, even though macrophages are thought to be poor APC for initiating T-cell responses. The in vivo morphology of the destruction of the rat and human glioma cells was closely examined. ${ }^{16,37}$ After subcutaneous injection, membrane M-CSF transduced gliomas began dying within $4 \mathrm{~h}$ of the development of the swelling and vacuolization process of paraptosis. In the current study, a putative molecular mechanism was in-
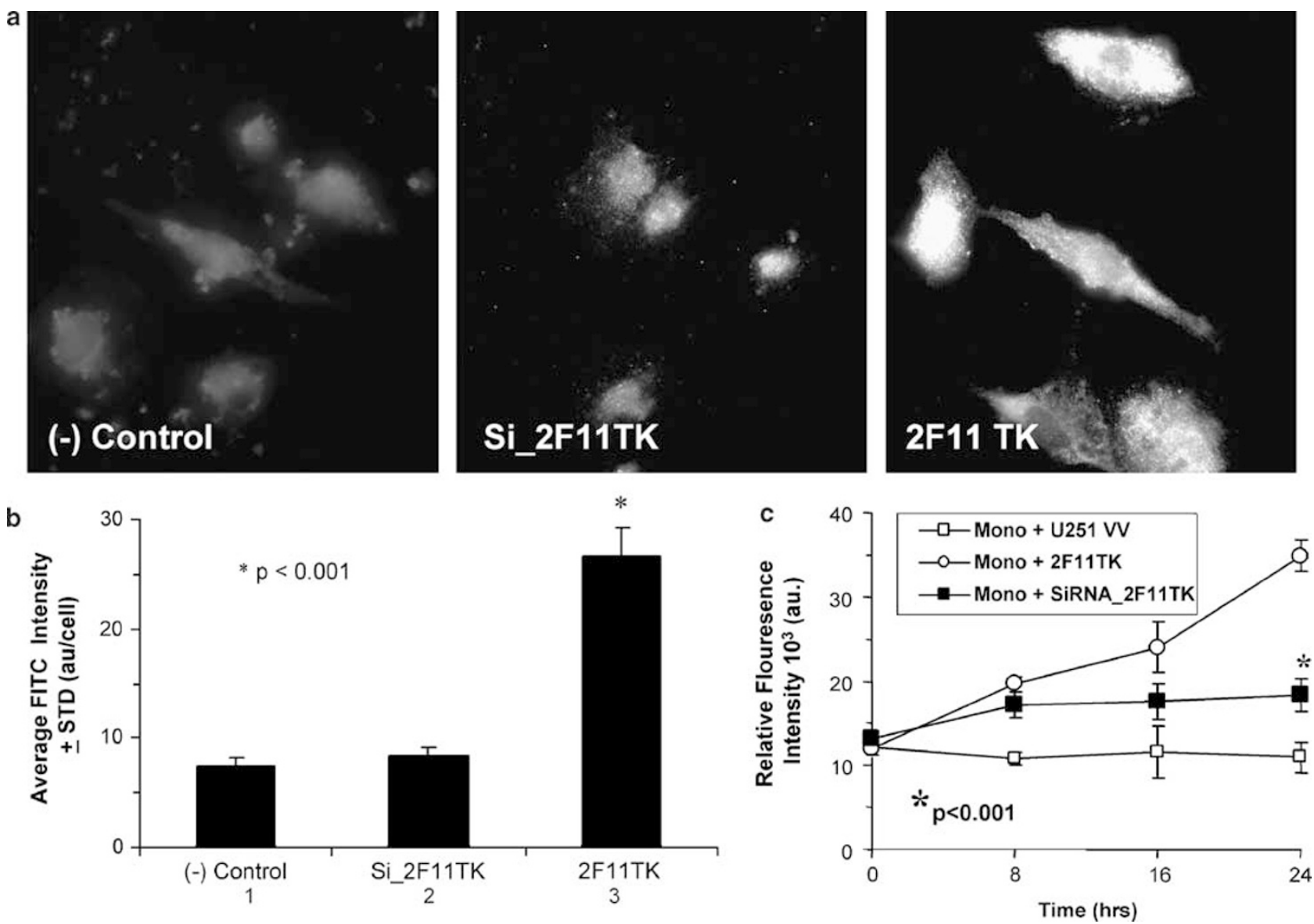

Figure 9 siRNA knockdown of BK channels within U251-2F11/TK cells shows reduced BK channel expression and makes the cells resistant to monocytes. U251-2F11/TK cells were transfected 4 days earlier with the siRNA BK channel primers. Left panels (a) were stained with the anti-BK channel antibody. Right panel: siRNA-transfected cells stained without the primary antibody but with the secondary antibody (negative control). Middle panel: siRNA-transfected cells stained with the anti-BK channel antibody. Left panel: non-transfected U251-2F11/TK stained with the anti-BK channel antibody showing strong staining. (b) A bar chart of the staining intensities of 10 cells taken from each treatment group. (c) U251 cells (U251-VV, U251-2F11/TK) and siRNAtransfected (primer set 1) (U251-2F11/TK) were preloaded with Vybrant CFDA fluorescent stain used for cytotoxicity. The human monocytes were added at a 10:1 monocyte:tumor ratio and the released fluorescence was monitored for the next $24 \mathrm{~h}$. Maximum release was 90300 arbitrary units. 
vestigated that could explain how human monocytes can kill cloned human mM-CSF-expressing U251-2F11/TK glioma cells. Others have postulated that oxygen induces NADPH450 reductase and hemoxygenase- 2 to make the secondary messenger, CO. ${ }^{20,21} \mathrm{CO}$ allows the opening of BK channels. We tested the hypothesis that within mM-CSF-expressing tumor target cells prolonged activation of the BK channels by the monocytes' respiratory burst, mimics many of the actions of tumoricidal macrophages responding to $\mathrm{mM}$-CSF-expressing U251 tumor cells, via the production of ROS. This proposed cytolytic mechanism explains how mM-CSF-transduced tumor cells are killed by human monocytes and can initiate antitumor immune responses.

Within 30 min of treatment with two different BK channel activators, phloretin and pimaric acid, the U251 glioma cells began swelling and forming vacuoles (Figure 3 ). BK channels were detected on the cell membrane by immunofluorescence staining. These membrane BK channels were functional as demonstrated using patch-clamping techniques (Figure 2). With the use of colocalization immunofluorescence techniques, BK channels were observed in the ER and the mitochondria (Figure 5). These two organelles are affected in paraptosis and this finding provides a rationale for why these organelles are specifically targeted in this cellular death pathway. The demonstration of BK channels in the ER probably represents the normal synthesis and transport of BK channels towards the membrane. Functional BK channels have also been detected in the mitochondria of gliomas. ${ }^{26}$ Forced BK channel opening disrupts normal ion homeostasis by expelling $\mathrm{K}^{+}$from the organelles and the cell. In turn, $\mathrm{Na}^{+}$cations and water enter the cell, resulting in organelle and overall cellular swelling. Cell swelling and vacuole formation was prevented by the use of iberiotoxin, a BK channel-specific inhibitor (Figure 3). Iberiotoxin also prevented monocytes from killing the U251-2F11/TK glioma cells (Figure 8). Gene silencing of the BK channel mRNA within the U251-2F11/TK cells significantly prevented monocytes from killing these cells (Figure 9).

The ER and mitochondria also store $\mathrm{Ca}^{+2}$ ions. Previously, two other groups of researchers have reported that $\mathrm{Ca}^{+2}$ ion disregulation induces paraptosis. ${ }^{45,46}$ In preliminary studies, an elevated intracellular $\mathrm{Ca}^{+2}$ level was maintained, as seen in fura-2 fluorescence studies, when BK channel activators are added (Hoa, unpublished data). BK channels are known as $\mathrm{Ca}^{+2}$-dependent-voltage-dependent $\mathrm{K}^{+}$channels, so the present work is consistent with that of Rao et $a l^{45}$ and Jambrina et al. ${ }^{46}$ Thus, it is possible that there are common effector mechanisms involving disrupted ionic homeostasis that can lead to paraptosis.

The proposed mechanism through which monocytes and macrophages can produce death in mM-CSF-expressing cells by paraptosis is shown in Figure 10. At time 0 (Figure 9a), before monocytes have contact with the mM-CSF tumor cells, the tumor cell possesses normal homeostasis. Intracellular ATP, $\mathrm{K}^{+}$and $\mathrm{Na}^{+}$are at baseline physiological levels; that is, high $\mathrm{K}^{+}$and low $\mathrm{Na}^{+}$intracellular concentrations. When the monocytes contact the mM-CSF cell via the M-CSF receptor (Figure 9b), ROS are produced, although there may be other mediators involved (see below). ROS allow hemoxygenase and P450 reductase to enzymatically produce $\mathrm{CO}$, which acts as a secondary signal. $\mathrm{CO}$ mediates the opening of $\mathrm{BK}$ channels on the cell membrane, ER and mitochondria, expelling pooled stores of $\mathrm{K}^{+}$. As the cell expels $\mathrm{K}^{+}, \mathrm{Na}^{+}$cations enter, maintaining the cells' electroneutrality. When $\mathrm{Na}^{+}$enters the cell, water also enters, producing the observed cellular swelling. Vacuolization occurs when the ER and mitochondria swell. Cellular homeostatic mechanisms expel the elevated intracellular $\mathrm{Na}^{+}$through the ATP-dependent $\mathrm{Na}^{+} / \mathrm{H}^{+}$antiporter. ${ }^{47}$ Inhibition of the $\mathrm{Na}^{+} / \mathrm{H}^{+}$antiporter has been noted to induce paraptosis in cerebellar neurons. ${ }^{48}$ When BK channels are fully engaged in response to the monocyte mediators, the cell remains swollen. The cell expends more ATP to expel the unwanted $\mathrm{Na}^{+}$ions. As the mitochondria are targeted in paraptosis, the disruption of this organelle reduces the cell's ability to generate the required levels of ATP necessary to maintain ionic homeostasis. Several groups have reported that the loss of ATP within cells resulted in the development of a necrosis forming pathway. ${ }^{49-52}$ Attacking the generation of ATP eventually prevents the cell from keeping a proper volume. Hence, the mitochondria and cells will eventually run out of ATP with subsequent osmotic rupture. The gathered $\mathrm{Cr}^{51}$ release data indicates that actual membrane rupture occurs between 8 and $12 \mathrm{~h}$. Hence, simple cell swelling and vacuolization does not induce immediate cell death, but requires further downstream events; this is consistent with the slow depletion of intracellular ATP described in our predicted model.

Cell swelling can be induced by monocyte/macrophagederived mediators such as $\mathrm{H}_{2} \mathrm{O}_{2}$ (data not shown), ${ }^{53}$ peroxynitrite, ${ }^{54}$ arachidonic acid ${ }^{55,56}$ and its metabolites, leukotrienes and prostaglandins. ${ }^{57,58}$ In vivo there is evidence that inducible nitric oxide synthase and peroxynitrite are present at the subcutaneous mM-CSF tumor cell rejection sites. ${ }^{16,37}$ In the current study the exact macrophage-derived mediator responsible for paraptosis induction was not addressed. ROS were detected within $18 \mathrm{~min}$ and exogenously added $\mathrm{H}_{2} \mathrm{O}_{2}$ and arachidonic acid (data not shown) caused cellular swelling and vacuolization of the U251 glioma cells. Therefore, the monocyte driven mechanisms producing cellular death of the mM-CSF transduced glioma cells are multidimensional and have the potential for synergistic interactions.

In summary, the results of this study indicate that human monocytes/macrophages can kill mM-CSF-transduced cells via a form of cell death pathway called paraptosis. The mechanism appears to be activation of potassium ion channels called BK channels, as two different BK channel activators produced this effect. Paraptosis induction was blocked by using a specific BK channel inhibitor. The swelling and 


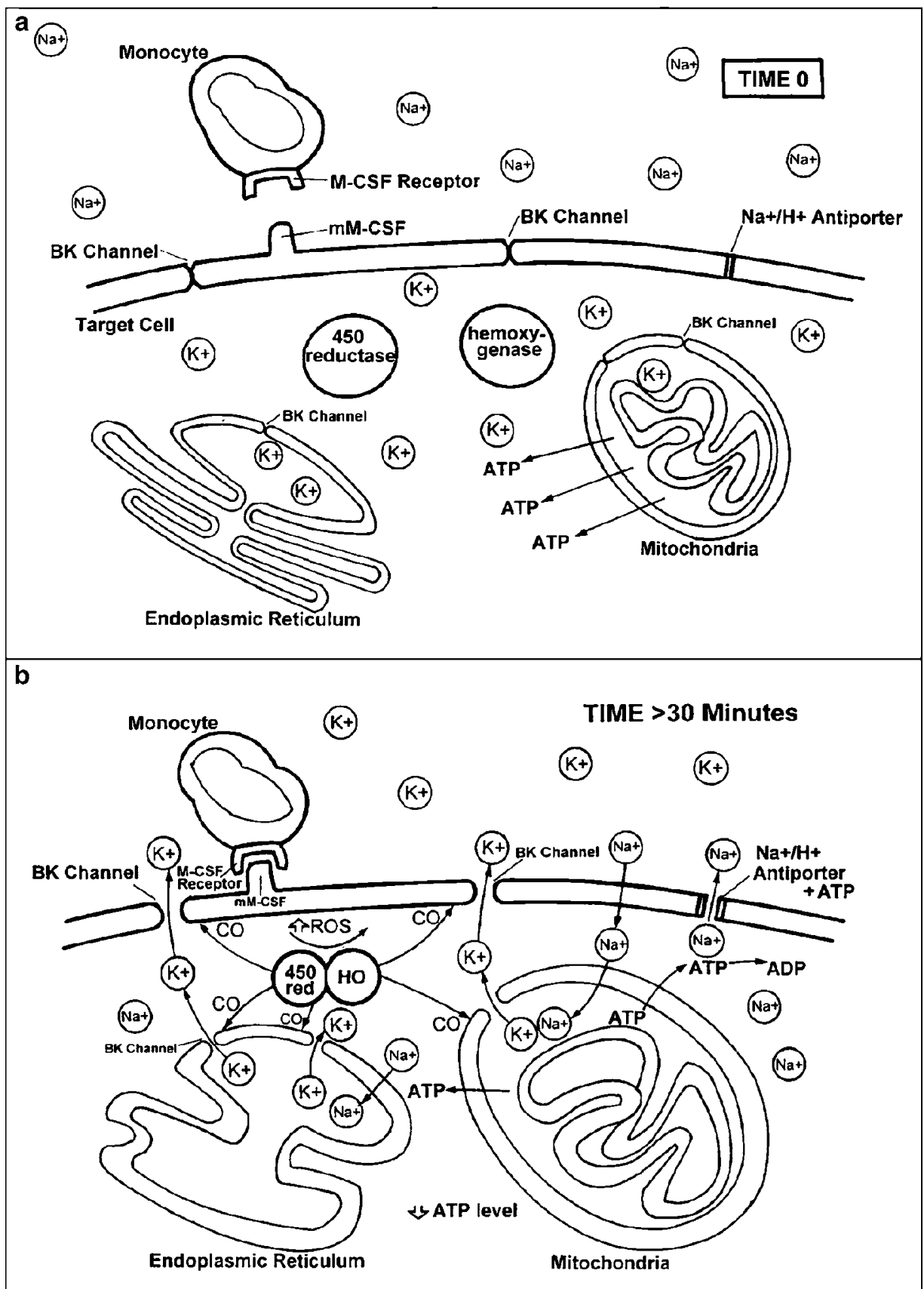

Figure 10 Proposed mechanism by which monocytes produce death in mM-CSF U251 glioma cells. (a) Time before the monocytes engage the mM-CSFexpressing cells is indicated. The target cell has high intracellular $\left[\mathrm{K}^{+}\right]$and low $\left[\mathrm{Na}^{+}\right]$levels; the $\mathrm{BK}$ and $\mathrm{Na}+/ \mathrm{H}+$ antiporter channels are closed. (b) The actions after the monocytes that have responded to the MM-CSF tumor cells are shown; ROS are formed and have induced changes within the targeted cells. ROS stimulates the NADPH450 reductase (450 red) and hemoxygenase-2 $(\mathrm{HO})$ to produce the secondary messenger, $\mathrm{CO}$. CO opens the BK channels expelling intracellular $\mathrm{K}^{+}$ions. $\mathrm{Na}^{+}$ions replace the exported $\mathrm{K}^{+}$ions. Water also enters with the $\mathrm{Na}^{+}$, inducing first swelling and then vacuolization. The antiporter is opened utilizing ATP to expel the unwanted intracellular $\mathrm{Na}^{+}$ions. As the mitochondria are swollen, the normal production of ATP is reduced. Eventually, antiporter function can no longer be supported and the cell osmotically lyses.

vacuolization effect was seen within $1 \mathrm{~h}$, but the cells were not actually killed until $8-12 \mathrm{~h}$ of continuous exposure to forced BK channel opening had occurred. Functional BK channels were found on the cell membranes of human U251 glioma cells. BK channels were also detected within the ER and mitochondria, which are the targeted organelles of paraptosis. All swelling and vacuolization effects induced by BK channel activators were inhibited by the use a BK channel inhibitor. Iberiotoxin also prevented human monocytes from killing the mM-CSF-expressing U251 cells. 


\section{ACKNOWLEDGEMENT}

The authors have no conflicting financial interests. This study was funded in part from grants obtained from the Veterans Affairs Medical Center (HTW, MRJ) and the NIH Grant CA77802 R01 (MRJ) and the Avon Breast Cancer Foundation via the University of California at Irvine Cancer Research Program (MRJ). HHMI Grant 52002663 (GV and MM, M Merryfield-CSULB PI), Research Corporation Cottrell College Science Award CC6155 (MM). None of the authors have any duality of interest.

1. Sperandio S, de Belle I, Bredesen DE. An alternative, non-apoptotic form of programmed cell death. Proc Natl Acad Sci USA 2000;97:14376-14381.

2. Lazarowski ER, Homolya L, Boucher RC, et al. Direct demonstration of mechanically induced release of cellular UTP and its implication for uridine nucleotide receptor activation. J Biol Chem 1997;272: 24348-24354.

3. Yang $\mathrm{H}$, Wang $\mathrm{H}, \mathrm{Czura} \mathrm{CJ}$, et al. The cytokine activity of HGMB1. J Leukocyte Biol 2005;78:1-8.

4. Melcher A, Todryk S, Hardwick N, et al. Tumor immunogenicity is determined by the mechanism of cell death via induction of heat shock protein expression. Nat Med 1998;4:581-587.

5. Gallucci S, Lolkema M, Matzinger P. Natural adjuvants: endogenous activators of dendritic cells. Nat Med 1999;5:1249-1255.

6. Gallucci S, Matzinger P. Danger signals: SOS to the immune system. Curr Opin Immunol 2001;13:114-119.

7. Wylie AH, Kerr JFR, Currie AR. Cell death: the significance of apopotosis. Int Rev Cytol 1980;68:251-306.

8. Cohen JJ. Apoptosis. Immunol Today 1993;14:126-130.

9. Witham TF, Erff ML, Okada $\mathrm{H}$, et al. 7-Hydroxystaurosporine-induced apoptosis in $9 \mathrm{~L}$ glioma cells provides an effective antigen source for dendritic cells and yields a potent vaccine strategy in an intracranial glioma model. Neurosurgery 2002;50:1327-1334.

10. Barker RN, Erwig L, Pearce WP, et al. Differential effects of necrotic or apoptotic cell uptake on antigen presentation by macrophages. Pathobiology 1999;67:302-305.

11. Voll RE, Herrmann $M$, Roth $E A$, et al. Immunosuppressive effects of apoptotic cells. Nature 1997;390:350-351.

12. Steinman RM, Turley $S$, Mellman I, et al. The induction of tolerance by dendritic cells that have captured apoptotic cells. J Exp Med 2000;191:411-416.

13. Sauter B, Albert ML, Francisco L, et al. Consequences of cell death: exposure to necrotic tumor cells, but not primary tissue cells or apoptotic cells, induces the maturation of immunostimulatory dendritic cells. J Exp Med 2000;191:423-433.

14. Fadok VA, Bratton DL, Konowaal $A$, et al. Macrophages that have ingested apoptotic cells in vitro inhibit pro-inflammatory cytokine production through autocrine/paracrine mechanisms involving TGF- $\beta$, PGE2 and PAF. J Clin Invest 1998;101:890-898.

15. Reiter I, Krammer B, Schwamberger G. Differential effect of apoptotic vs necrotic tumor cells on macrophage anti-tumor activities. J Immunol 1999;163:1730-1732.

16. Jadus MR, Chen Y, Boldaji MT, et al. Human U251MG glioma cells expressing the membrane form of macrophage colony-stimulating factor (mM-CSF) are killed by human monocytes in vitro and are rejected within immunodeficient mice via paraptosis that is associated with increased expression of three different heat shock proteins. Cancer Gene Ther 2003;10:411-420.

17. Weaver $A K$, Liu $X$, Sontheimer $\mathrm{H}$. Role for calcium-activation channels (BK) in growth control of human malignant glioma cells. J Neurosci Res 2004;78:224-234.

18. Ransom $C B$, Sontheimer $\mathrm{H}$. BK channels in human glioma cells. J Neurophysiol 2001;85:790-801.

19. Liu X, Chang Y, Reinhart PH, et al. Cloning and characterization of glioma BK, a novel BK channel isoform highly expressed in human glioma cells. J Neurosci 2002;22:1840-1849.

20. Hoshi T, Lahiri S. Oxygen sensing: it's a gas. Science $2004 ; 306$ : 2050-2051.

21. Williams SE, Wootton $P$, Mason HS, et al. Hemoxygenase-2 is an oxygen sensor for a calcium-sensitive potassium channel. Science 2004;306:2093-2097.

22. Koerper S, Nolte F, Markus T, et al. The K+ channel openers diazoxide and NS1619 induce depolarization of mitochondria and have differential effects on cell $\mathrm{Ca}^{2+}$ in CD34+ cell line KG-1a. Exp Hematol 2002;31:9-15.

23. Spergel DJ, Catt KJ, Rojas E. Immortalized GnRH neurons express largeconductance calcium-activated potassium channels. Neuroendocrinology 1996;63:101-111.

24. Grunnet M, Hay-Schmidt A, Klaerke DA. Quantification and distribution of big conductance $\mathrm{Ca}^{2+}$-activated $\mathrm{K}^{+}$channels in kidney epithelia. Biochim Biophys Acta 2005;1714:114-124.

25. Ransom CB, Xiaojin L, Sontheimer H. BK channels in human glioma cells have enhanced calcium sensitivity. Glia 2002;38:281-291.

26. Debska G, Kicinska A, Dobrucki J, et al. Large-conductance K+ channel openers NS1619 and NS004 as inhibitors of mitochondrial function in glioma cells. Biochem Pharm 2003;65:1827-1834.

27. Debska G, Kicinska A, Skalska J, et al. Intracellular potassium and chloride channels: an update. Acta Biochimica Polonica 2001;48: 137-144.

28. Gabrilovich D. Mechanisms and functional significance of tumourinduced dendritic-cell defects. Nat Rev Immunol 2004;4:941-952.

29. Serafini P, Borrello I, Bronte V. Myeloid suppressor cells in cancer: recruitment, phenotype, properties, and mechanisms of immune suppression. Semin Cancer Biol 2006;16:53-65.

30. Grzelak A, Rychlik B, Bartosz G. Light-dependent generation of reactive oxygen species in cell culture media. Free Radical BioMed 2001;30:1418-1425.

31. Hamill OP, Marty A, Neher E, et al. Improved patch-clamp techniques for high-resolution current recording from cells and cell-free membrane patches. Pflugers Arch 1981;391:85-100.

32. Molleman A. Patch Clamping. Wiley Press: West Sussex, England, 2003.

33. Myers MP, Yang J, Stampe P. Visualization and functional analysis of a maxi-K channel (mSlo) fused to green fluorescent protein (GFP). Electronic J Biotechnol (online) 1999;2:3 www.ejbiotechnology.info/ content/vol2/issue3/full/3/index.html.

34. Pfaffl MW. A new mathematical model for relative quantification in real-time RT-PCR. Nucleic Acids Res 2001;29:e45.

35. Jadus MR, Irwin MC, Irwin MR, et al. Macrophages can recognize and kill tumor cells bearing the membrane isoform of macrophage colonystimulating factor. Blood 1996;87:5232-5241.

36. Dan $Q$, Sanchez $R$, Delgado $C$, et al. Non-immunogenic murine hepatocellular carcinoma Hepa1-6 cells expressing the membrane form of macrophage colony stimulating factor are rejected in vivo and lead to CD8 T cell immunity against the parental tumor. Mol Ther 2001;4:427-437.

37. Chen $\mathrm{Y}, \mathrm{Xu} \mathrm{Q}$, Williams $\mathrm{CC}$, et al. Living T9 glioma cancer cells expressing membrane macrophage colony stimulating factor produce immediate tumor destruction by polymorphonuclear leukocytes, and macrophages via a 'paraptosis'-induced pathway that promotes systemic immunity against intracranial T9 gliomas. Blood 2002;100:1373-1380.

38. Graf MR, Jadus MR, Wepsic HT, et al. Development of systemic immunity to glioblastoma multiforme using tumor cells genetically engineered to express the membrane bound isoform of macrophage colony stimulating factor (CSF-1). J Immunol 1999;163:5544-5551.

39. Sanchez R, Williams CC, Daza JL, et al. T9 glioma cells expressing membrane macrophage colony stimulating factor produce CD4+ associated protective immunity against T9 intracranial gliomas and systemic immunity against different syngeneic gliomas. Cell Immunol 2002;216:1-10.

40. Williams CC, Trinh H, Tran TV, et al. Membrane expression of macrophage colony stimulating factor on MADB106 breast cancer cells is not associated with in vitro cytotoxicity by macrophages but is associated with the induction lasting tumor immunity against syngeneic breast cancer cells in vivo. Mol Ther 2001;3:216-221.

41. Scholl SM, Pallud C, Beuvon F, et al. Anti-colony-stimulating factor-1 antibody staining in primary breast adenocarcinomas correlates with marked inflammatory cell infiltrates and prognosis. JNCI 1994; 86:120-126.

42. Ramakrishnan S, Xu FJ, Brandt SJ, et al. Constitutive production of macrophage colony-stimulating factor by human ovarian and breast cancer cell lines. J Clin Invest 1989;83:921-926.

43. Chunhai $\mathrm{H}$, Parney IF, Roa WH, et al. Cytokine and cytokine receptor mRNA expression in human glioblastomas: evidence of Th1, Th2 and Th3 cytokine dysregulation. Acta Neuropathol 2002;103:171-178. 
44. Jadus MR, Wepsic HT, Jeffes EWB. The biology and potential anticancer uses of the membrane form of macrophage colony stimulating factor. Recent Res Dev Immunol 1999;1:267-281.

45. Rao RV, Ellerby HM, Bredesen DE. Coupling endoplasmic reticulum stress to the cells death program. Cell Death and Different 2004;11:373-380.

46. Jambrina $\mathrm{E}$, Alonso $\mathrm{R}$, Alcada $\mathrm{M}$, et al. Calcium influx through receptoroperated channel induces mitochondria-triggered paraptotic cell death. J Biol Chem 2004;278:14134-14145.

47. Cassel D, Katz M, Rotman M. Depletion of cellular ATP inhibits $\mathrm{Na}+/ \mathrm{H}+$ antiport in cultured human cells. J Biol Chem 1986;261:5460-5466.

48. Schneider D, Gerhardt E, Bock J, et al. Intracellular acidification by inhibition of the $\mathrm{Na}+/ \mathrm{H}+$-exchanger leads to caspase-independent death of cerebellar granule neurons resembling paraptosis. Cell Death Differ 2004;11:760-770.

49. Nioctera P, Melino G. Regulation of the apoptosis-necrosis switch Oncogene 2004;23:2757-2765.

50. Eguchi Y, Shimuzu S, Tsujimoto Y. Intracellular ATP levels determine cell death fate by apoptosis or necrosis. Cancer Res 1997;57: $1835-1840$.

51. Nicotera $\mathrm{P}$, Leist $\mathrm{M}$, Fava $\mathrm{E}$, et al. Energy requirement for caspase activation and neuronal cell death. Brain Pathol 2000;10:276-282.
52. Leist $M$, Single $B$, Castoldi AF, et al. Intracellular adenosine triphosphate (ATP) concentration: a switch in the decision between apoptosis and necrosis. J Exp Med 1997;185:1481-1486.

53. Simon F, Varela D, Riveros $A$, et al. Non-selective cation channels and oxidative stress-induced cell swelling. Biol Res 2002;35:215-222.

54. Estevez AG, Radi R, Barbeito L, et al. Peroxynitrite-induced cytotoxicity in PC12 cells: evidence for an apoptotic mechanism differentially modulated by neurotrophic factors. J Neurochem 1995;65: 1543-1550.

55. Dutta AK, Okada Y, Sabirov RZ. Regulation of an ATP-conductive largeconductance anion channel and swelling-induced ATP release by arachidonic acid. J Physiol 2002;542.3:803-816.

56. Winkler AS, Baethmann A, Peters J, et al. Mechanisms of arachidonic acid induced glial swelling. Mol Brain Res 2000;76:419-423.

57. Peters-Golden M, McNish RW, Hyzy R, et al. Alterations in the pattern of arachidonate metabolism accompany rat macrophage differentiation in the lung. J Immunol 1990;144:263-270.

58. Shimizu $T$, Naruse $M$, Takeda $M$, et al. Mechanism of $P_{G E}$-induced cell swelling in distal nephron segments. Am J Physiol 1992;263: F824-F832. 